\title{
Condutas de diagnóstico
}

\section{Conducts of diagnosis.}

\author{
Manoel Sant'Ana Filho* \\ Claiton Heitz ** \\ Pantelis Varvaki Rados*** \\ João Jorge Diniz Barbachan **** \\ Maurício Roth Volkweis ${ }^{* * * * *}$
}

\section{Resumo:}

Os autores apresentam revisão de literatura e análise de quatro casos clínicos a respeito das condutas que devem ser seguidas para a obtençăo de um correto diagnostico.

\section{Summary:}

The authors present review of literature and analysis of four clinical cases abording the steps that should be follow to get to a right diagnosis.

\section{UNITERMOS:}

\author{
Patologia bucal; Diagnóstico \\ oral; Cistos tumores \\ odontogenicos; Tumores \\ malignos.
}

\section{Introdução:}

O diagnóstico das lesões bucais é fundamental para que possamos realizar um correto tratamento visando o menor dano possível ao paciente, bem como a sua cura mais rápida. Dessa forma, devemos obtêlo de maneira precisa e rápida. Diversas técnicas tem sido desenvolvidas, mas a que permanece como a mais simples e eficaz de ser executada oferecendo maior segurança no diagnóstico é a biópsia seguida de exame histopatológico. Este procedimento deve ser sempre realizado quando qualquer tecido for removido da cavidade bucal com finalidade terapêutica ou de diagnóstico.

Abordaremos quatro casos clínicos em que a correta conduta diagnóstica permitiu a identificação da doença e sua terapêutica adequada.

\section{Revisão de Literatura:}

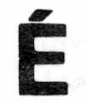
responsabilidade do cirurgiãodentista a descoberta e o diagnóstico de várias condições patológicas que envolvem a cavidade bucal e as regiőes circunvizinhas, uma grande variedade de lesões bucais pode ser diagnosticada pela associaçăo de manifestações clínicas, radiográficas e anamrese ${ }^{1}$. Problemas de difícil diagnóstico são particularmente su- perados por famosos profissionais graças aos seus exames criteriosos. É tendência comum ao clínico menos experiente estabelecer um diagnóstico provável ao início da avaliação anamnética do paciente e então questioná-la de forma a confirmar o seu diagnóstico 6 .

Entretanto, muitas alterações necessitam exames complementares para o seu diagnóstico ${ }^{1}$. Entre todos os exames laboratoriais, a biópsia é aquele que alcança os mais elevados percentuais de acerto de diagnósti$\mathrm{Co}^{2}$. Apesar de sua consagração como valioso meio de diagnóstico, alguns não lhe dão a verdadeira importância, realizando intervenções cirúrgicas de grande vulto sem a pré-

* Professor de Patologia Geral e Buco-Dentária da U.F.R.G.S. e P.U.C.R.S., Professor do curso de Mestrado em Patologia Eucal da U.F.R.G.S., Professor do curso de Mestrado em Cirurgia e Traumatologia Euco-Maxilo-Facial da P.U.C.R.S.

* Professor de Cirurgia da P.U.C., Mestre em Cirurgia e Traumatologia Buco-Maxilo-Facial.

* * Professor de Patologia Geral e Euco-Dentária da U.F.R.G.S. e P.U.C.R.S., Professor do curso de Mestrado em Patologia Bucal da U.F.R.G.S.

*** Professor de Patologia Geral e Buco-Dentária da U.F.R.G.S., Professor Coordenador do curso de Mestrado em Patologia Bu$\mathrm{cal}$ da U.F.R.G.S.

***** Aluno de Graduação da U.F.R.G.S., Bolsista de Iniciação Cientifica do CNPq.
R. Fac. Odontol.
V. 34
N. 1 
via e obrigatória biópsia das lesões a serem tratadas ${ }^{8}$.

Para a compreensão dos fatores que levam os profissionais a furtarse à biópsia, poder-se-ia englobá-los em três grupos: incapacidade técni$\mathrm{ca}$, temor psicológico e desconhecimento do aspecto clínico das patologias bucais ${ }^{1}$, contudo a biópsia é, em geral, um procedimento simples que não deve ser considerada como uma cirurgia porque não são necessários conhecimentos e experiências expecíficas $^{2,7}$. A biópsia não limitase ao diagnóstico de lesões malígnas ou tumores, sendo necessária na identificação de qualquer lesão insólita 2,11 .

Devemos considerar a biópsia como parte de um processo que compreende a descoberta de uma lesão, seu diagnóstico provável e a necessidade de um diagnóstico definitivo para o tratamento adequado do paente ${ }^{2}$.

Estará indicada para o diagnóstico de patologias 5,8 , avaliação da malignidade de tumores, determinar se a exérese da lesão foi adequada, observar o resultado de certas formas terapêuticas ${ }^{8}$, confirmação de enfermidades sistêmicas ${ }^{5}$. É formalmente contra-indicada em lesões melânicas e vasculares $2,3,5,8$.

É imprescindível que o cirurgiåodentista remeta todo o tecido removido da cavidade bucal para exame histopatológico e que esteja ciente que isso induzirá um início de tratamento efetivo mais rápido e adequado, algumas vezes preservando a vida do paciente ${ }^{1}$.

A manipulação do tecido removido para exame histopatológico deve obedecer certos critérios para evitar a formaçõao de artefatos histológicos durante o seu processamento ${ }^{4}$, a saber: boa avaliação clínica para selecionar a melhor área para a bióp$\mathrm{sia}^{4}$, se possível incluindo margem de tecido normal8; deve haver quantidade suficiente de tecido para a análise ${ }^{3,4}$, incluindo boa profundidade ${ }^{8}$; manipulação cuidadosa do tecido ${ }^{3}$; não contaminar o tecido com material estranho ${ }^{3}$, inclusive solução anestésica ${ }^{3}$; fixação da amostra logo após sua remoção $2,3,7,8$; identificar adequadamente a amostra e fornecer dados clínicos suficientes que permitam ao patologista um diagnóstico o mais definitivo possível $^{2,4,5,8}$.

Cabe ainda salientar que em doenças cujas características clínicas e evolução permitam um diagnóstico eminentemente clínico, como as aftas, herpes primário, etc., ou naquelas cujas características clínicas se necessita ter a mão o resultado de outros exames complementares como a sífilis, não justificam a realização de biópsia ${ }^{3}$.

Devemos entender como biopsia a remoção de um fragmento de tecido vivo para exame histopatológi$\mathrm{Co}^{2}$, envolvendo o processamento laboratorial desse material, a confecção de lâminas seguido de análise e descrição microscópica com diagnóstico histopatológico.

\section{Materiais e Métodos:}

$F$ oram selecionados quatro casos clínicos dos Laboratórios de Patologia da Faculdade de Odontologia da Universidade Federal do Rio Grande do Sul e do Instituto de Biociências da Pontifícia Universidade Católica do Rio Grande do Sul, onde o diagnóstico histopatológico não concordou com o diagnóstico clínico mas a preservação do paciente e a análise laboratorial do material biopsiado resultou na cura.

Todas as peças foram fixadas em formol a $10 \%$ e coloridas por Hematoxilina e Eosina (H/E).

Os dados pessoais dos pacientes não foram considerados para a seleção dos casos.

Procedeu-se a descrição da história clínica de cada caso, aspecto clínico da lesão, condu ta adotada, exame microscópico e comentamos as atitudes adotadas relacionando-as com os resultados obtidos e o preconizado na literatura.

\section{Apresentação dos casos clínicos:}

\section{Caso 1.}

Paciente L.B.S., de 68 anos, sexo masculino, casado, branco, apresentava junto a um dente molar inferior, localizado por lingual, uma lesão de cor vermelha, forma irregular, consistência mole, sésșil e de inserção mucosa. O paciente relatava dor no local e evolução de aproximadamente um ano. Devido a cárie existente no dente envolvido esse foi extraído supondo-se tratar-se de uma fístula. Com a remoção do suposto agente causal não houve regressão de lesão, o que levou a uma mudança de conduta optando-se pela realização de uma biópsia total. Foi removido um fragmento de tecido mole de forma elíptica, medindo $8 \times 4 \mathrm{~mm}$.

Ao exame microscópico notava-se a presença de proliferação neoplásica maligna de células epiteliais de revestimento, mostrando hipercromasia, atipia celular e mitoses aberrantes. $\mathrm{O}$ tecido conjuntivo apresentava também infiltrado inflamatório crônico sobreposto. O diagnóstico histopatológico é, portanto, carcinoma epidermóide indiferenciado.

Se o diagnóstico clínico supunha um processo inflamatório, e a remoção do agente causal determinaria a involução da fístula. Contudo o acompanhamento do paciente após escolhida uma forma terapêutica nos possibilitou avaliarmos a evolução da lesão e considerarmos a realização de biópsia seguida por exame histopatológico uma vez que esses são os métodos mais simples e com maior índice de certeza para a obtenção de um diagnóstico definitivo.

$\mathrm{O}$ abandono do paciente após realizada a exodontia baseada na "certeza clínica" de que não erramos diagnósticos que parecem evidentes levaria a evolução do carcinoma trazendo conseqüências mórbidas para o paciente. Dessa forma, o acompanhamento periódico de qualquer paciente após adotada uma medida terapêutica deve ser atitude comum $\theta$ 
habitual a qualquer cirurgião-dentista.

\section{Caso 2.}

O paciente S.S., de 40 anos, sexo masculino, branco, apresentava abaulamento vestibular associado a mobilidade dentária na região da bateria labial anterior superior (fig. 1). Havia historia de tratamento endo dantico nos dentes 11, 12 e 24 . O paciente apresentava crises de agudizaçăo com dor a qual regredia com o uso de antibioticoterapia, supondo uma lesåo inflamatória de origem apical.

O exame radiográfico mostra extensa área radiolúcida do tipo ćstico, prolongando-se até o assoaIho nasal e seio maxilar direito. Como exames complementares realizou-se punção, onde o material coletado foi líquido citrino, e novas tomadas radiográficas com contraste visando obter os limites da lesão.

O diagnóstico clínico e radiográfico foi de uma lesão cística periapical. Optou-se pela realização de uma bibpsia total em ambiente hospitalar. Apesar da aparente obviedade do diagnóstico, o material foi examinado microscopicamente, sendo um tecido epitelial de poucas camadas de células, revestindo uma cavidade irregular com quantidades variáveis de ceratina na delgada cápsula fibrosa (fig. 2), observa-se denso infiltrado inflamatório crônico, áreas com tecido bsseo e cartilaginoso com características normais, sendo, portanto, o diagnóstico histopatológico de cisto odontogênico ceratinizado.

Graças a rotina de enviarmos todo o material removido da cavidade bucal para exame histopatológico, obtivemos o diágnóstico definitivo da lesão. Caso tratássemos de uma lesão apical de origem inflamatória teríamos como medida terapêutica a remoção do agente causal, que no paciente em questão seria o retratamento dos canais radiculares dos dentes envolvidos. Todavia, a presença deste suposto agente agressor não estava relacionada a lesão por-

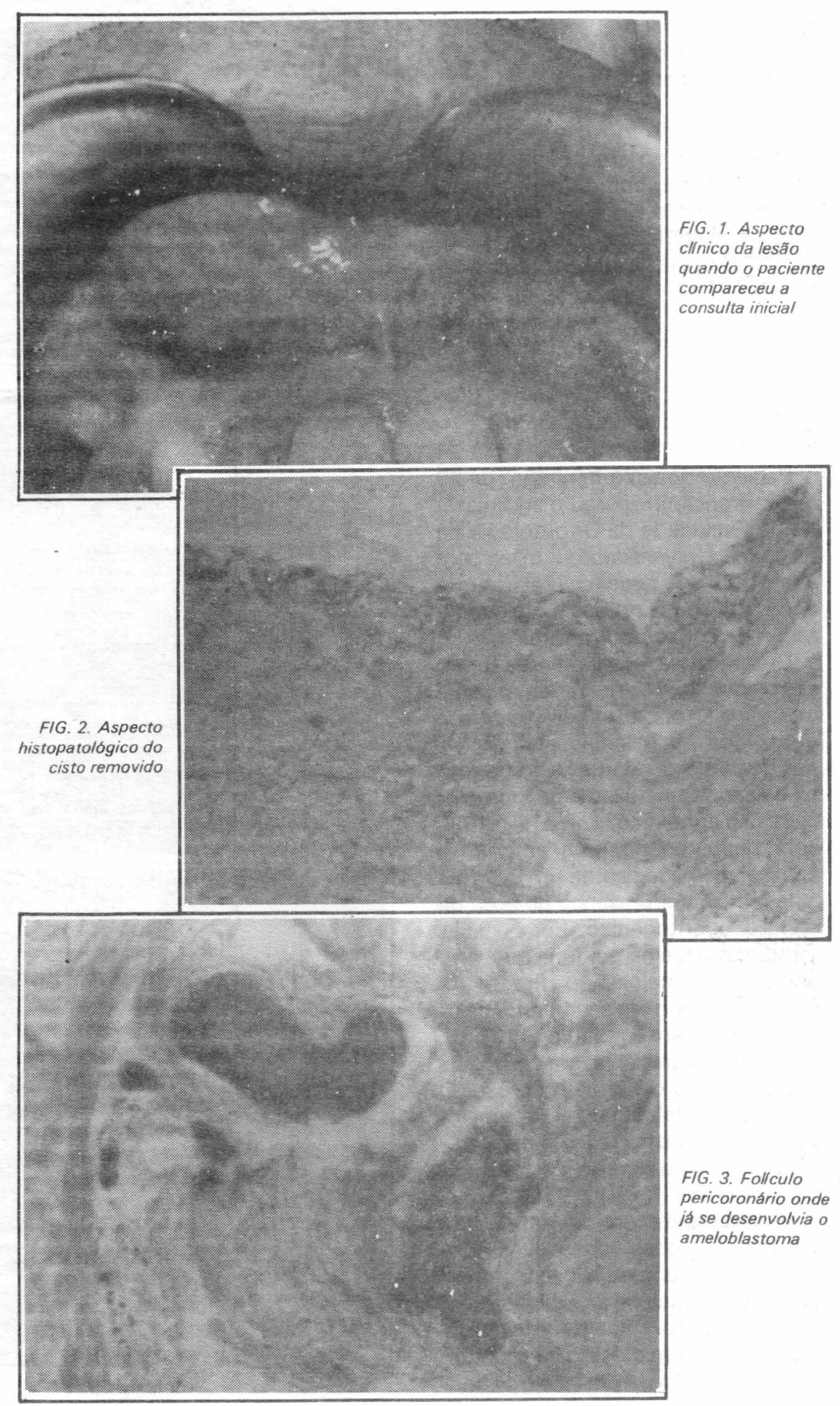


que o cisto odontogênico ceratinizado origina-se a partir da lâmina dentária ou do órgão do esmalte, exige tratamento cirúrgico com cuidadosa curetagem e possue um alto índice de recidiva, o que justifica controle radiográfico periódico do paciente.

Um erro de diagnóstico neste caso induziria a um tratamento inadequado ao paciente, com a manutenção do crescimento do cisto causando como conseqüência desde má posição dentária até fratura patológica do osso maxilar.

\section{Caso 3.}

Paciente do sexo feminino, de 20 anos, branca, procurou o ambulatório da Faculdade de Odontologia da Pontifícia Universidade Católica para a remoção dos terceiros molares que encontravam-se retidos, para a realização de correção ortodôntica.

Durante uma mesma sessão foram removidos os dois terceiros molares inferiores. Após a exodontia foram removidos os folículos pericoronários de ambos os dentes e como rotina enviados para exame histopatológico. O diagnóstico clínico foi de folículo pericoronário para ambos. A análise microscópica de um dos foliculos revelou a presença de ilhas de epitélio odontogênico, com células cilíndricas altas na periferia que lembram o pré-ameloblasto (fig. 3). As ilhas continham em seu interior células que lembram o retículo estrelado. Essas estruturas estavam dispostas em um tecido conjuntivo fibroso. 0 diagnóstico definitivo foi de ameloblastoma. $\mathrm{O}$ outro folículo pericoronário foi considerado histologicamente normal (fig. 4).

Na radiografia pré-operatória não era possível observar-se alterações da imagem compatível com a imagem radiográfica de ameloblastoma.

Ambos os folículos foram acondicionados em um mesmo frasco, sem a discriminação da posiçăo dos den-

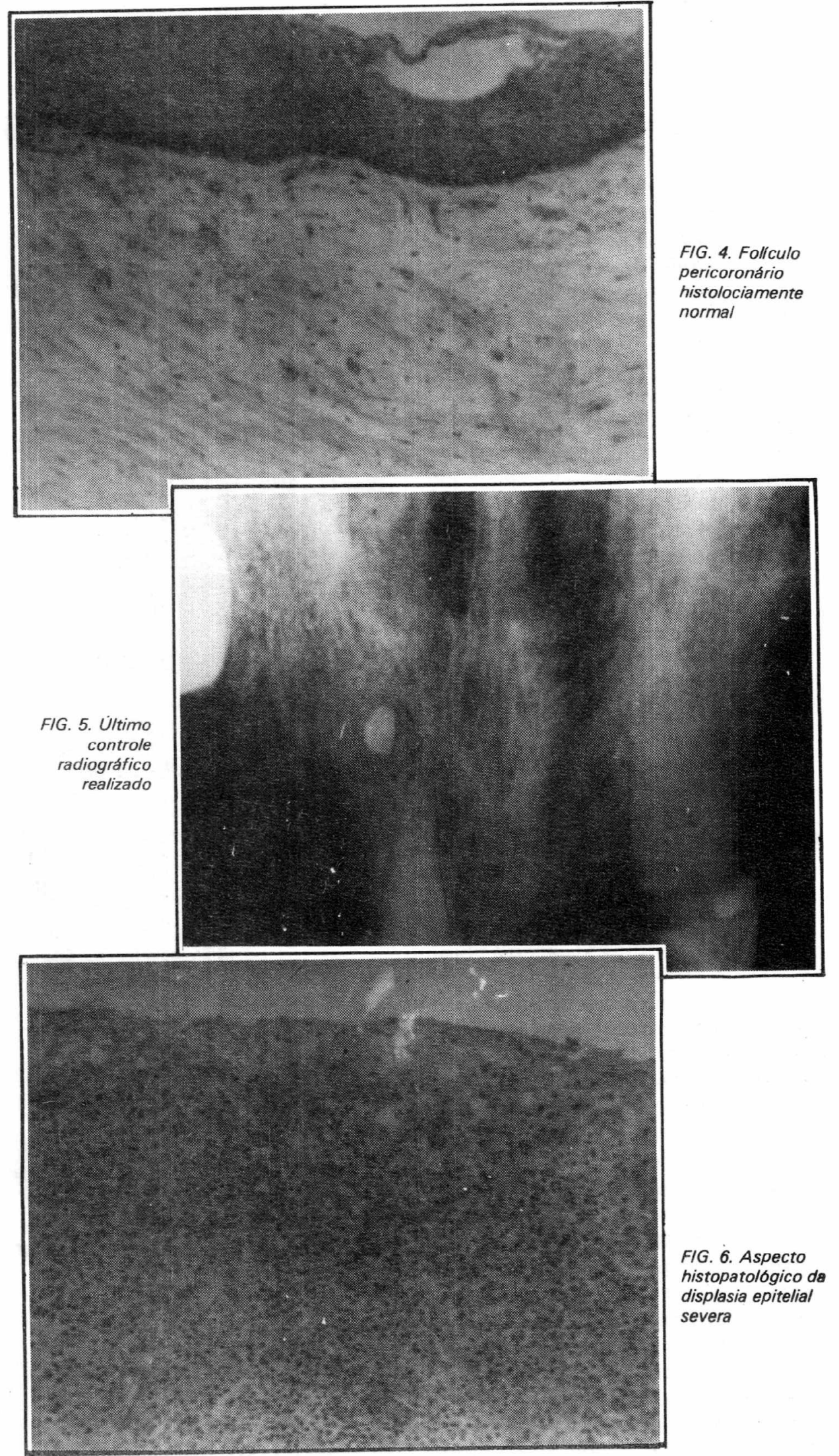

R. Fac. Odontol. 
tes, impossibilitando a identificação de qual lado pertencia o tumor. A paciente permanece em controle radiográfico perib́dico bilateral.

0 exame microscópico de folículo pericoronários deve ser rotina porque muitas vezes apesar de sua aparente inocência já pode ter havido o desenvolvimento de um cisto dentgero ou, como no presente caso, de um ameloblastoma. A diferença de conduta clínica frente a uma das lesões citadas e a de um folículo pericoronário normal justificam por si só o exame histopatológico desse tecido. Devemos ter presente a possibilidade de transformação do folículo por esse apresentar remanescentes epiteliais da embriogênese dentária com capacidade de proliferarem, originando lesões de diferentes naturezas.

O material de biópsia enviado para exame deve ser corretamente identificado e caso necessário utilizados mais de um frasco para o correto reconhecimento no laboratório. A mistura de materiais impossibilitou a identificação de que lado desenvolvia-se a lesão exigindo controle radiográfico bilateral da paciente.

\section{Caso 4.}

Paciente E.B., sexo feminino, 53 anos, cor branca, compareceu para avaliação e tratamento em junho de $1988 \mathrm{com}$ queixa de mobilidade em uma ponte fixa que envolvia os dentes $13,14,15,16$. O exame clínico mostrou mobilidade a pressão digital do canino superior direito, assintomático e sem linfoadenopatia satélite.

No exame radiográfico periapical pode-se observar uma fratura radicular no terço médio tomando um curso obliquo mais apicalmente, com afastamento dos fragmentos e com uma área radiolúcida em nível apical compatível com lesão periapical.

Realizou-se a remoção da ponte fixa e extraçăo a retalho com osteotomia prévia. No trans-operatório observou-se a fratura radicular e a re- moção da lesăo apical com o respectivo fragmento radicular e coletou-se este material para exame histopatologico. Fez-se sutura a pontos isolados e a cicatrização da mucosa ocorreu sem complicações.

A paciente foi acompanhada clínica e radiograficamente até fevereiro de 1991, não ocorrendo nenhuma alteração da mucosa e do osso envolvido na patologia (fig. 5).

Ao exame microscópico observase a presença de tecido conjuntivo densamente fibroso, com infiltrado inflamatório linfo-plasmocitário e a presença de epitélio com atipia celular, hipercromasia, perda de relação núcleo-citoplasma, sendo o diagnóstico histopatológico de cisto radicular com displasia epitelial severa (fig. 6). Todas as alterações das células epiteliais preservam a camada basal, não havendo invasão do tecido conjuntivo, sendo que a invasão deste pelo epitélio é o que diferencia a displasia epitelial severa de um carcinoma.

A grande incidência de lesões apicais e a sua característica de reversibilidade por tratar-se de um processo inflamatório não são justificativas para que o seu exame histopatológico não seja realizado. A sobreposição de alterações inflamatórias a tumores malignos pode ocorrer numa tentativa do organismo de limitar a agressão, contudo devemos diferenciar quando esse é apenas uma tentativa de resposta e não o fator determinante da lesão.

Quando removemos qualquer lesão apical o seu exame histopatológico está indicado para confirmaçăo do diagnóstico e orientação da conduta pós-operatória.

\section{Discussão e conclusōes:}

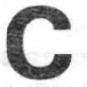
oncordamos com a afirmação de que e responsabilidade do cirurgião-dentista a descoberta e diagnóstico das patologias que en- volvem a cavidade bucal e as regiőes circunvizinhas ${ }^{1}$, devendo obedecer um rigoroso exame clínico e anamnese criteriosa ${ }^{6}$ para a soluçåo de problemas dessas regiőes. Nos casos apresentados as lesões foram identificadas por cirurgiőes-dentistas graças a correta proservação do paciente, indicaçăo de biópsia e exame histopatológico.

A biópsia está indicada em lesões que não cicatrizam ou não respondem a medidas terapêuticas adotadas dentro de um prazo de duas semanas $^{11}$, logo, na suposição de um processo inflamatório como no caso 1 a remoção do agente causal deveria solucionar a lesão mas sua persistência impõe a realização de biópsia ${ }^{11}$. 0 acompanhamento clínico e ou radiográfico dos pacientes deve ser realizado e a avaliação de certas medidas terapêuticas pode ser avaliada através da biópsia?

As contra-indicações formais recaem sobre lesões melânicas ou vasculares 2,3,5,8 e em nenhum dos casos haviam estas características.

Sempre que removermos qualquer tecido da cavidade bucal seja com finalidade terapêutica ou de diagnóstico este deverá ser examinado microscopicamente, sendo que diversos autores $1,4,5,7$ consideram biópsia e exame histopatológico como parte de um mesmo processo que não pode ser separado, não sendo feita uma distinção evidente entre uma situação e ou tra ${ }^{1,7}$ ou então considerando a biópsia como um procedimento inicial com o objetivo de possibilitar e fornecer material para exame e diagnóstico microscópico $^{2,4,5}$. A conduta de remeter os tecidos para exame histopatológico foi rotina nos casos presentes e somente assim obtivemos um diagnóstico final que nos quatro casos não foi concordante com o diagnóstico clínico.

Para a obtenção de um diagnóstico microscópico exato a correta manipulação e identificação do material removido é fundamental $4,5,7$ bem como informações precisas e pertinentes para o patologista $5,7,8$. Du- 
rante a fixação do material removido no Caso 3, estes não foram identificados quanto a sua origem, impedindo a definição de qual folículo pericoronário era patológico, neste caso a paciente necessita realizar, durante o período de proservação, controle radiográfico bilateral.

A técnica para a realização de biópsia não deve ser considerada como uma cirurgia ${ }^{2,7}$ porque não envolve conhecimentos e experiên- cias especificas, deve portanto fazer parte da rotina de procedimentos cllnicos realizados por qualquer cirurgião-dentista ${ }^{1,7}$ o qual não deve esquivar-se da sua realização ${ }^{1}$.

Para finalizar, achamos importante salientar as seguintes condutas para a obtenção de um correto diagnóstico:

1 - Criterioso exame clínico e anamnese do paciente.

2 - Acompanhamento do pa- ciente após adotada qualquer medida terapêutica.

3 - Indicação de biópsia quando a lesão persistir por um período superior a duas semanas ou quando a terapêutica exigir remoção cirúrgica da lesão.

4 - Adequada manipulação, fixação e identificação dos fragmentos removidos.

5 - Informações suficientes $\epsilon$ pertinentes ao patologista.

\section{Referências Bibliográficas}

1. ALVES, Maria Cristina R. A biópsia como método de diagnóstico: sua utilização pelos odontológos. Rev. Fac. Odont. Ribeirão Preto, Ribeirão Preto, v. 21, n. 2 , p. 114120 , jul-dez. 1984.

2. ARAÚJO, N. S. \& ARAÚJO, V. C. Patologia Bucal, São Paulo, Artes Médicas, 1984, 239 p., Cap. 1, Histopatologia Básica da Mucosa Bucal, p. 1-10.

3. COLOMBINI, Nelson E. P. Cirurgia Maxilo-Facial, São Paulo, Pancast Editorial, 1991, 803 p., Cap. 8 Biópsia, 157-174.

4. FICARRA, G. \& MCCLINTOCK, B. \& HANSEN, L.S. Artefacts Created During Oral Biopsy Procedures, J. Cranio-Max-Fac. Surg., Nova York, n: 15, p. 34-37, fevereiro, 1987.
5. GARCIA PENIN, A. \& BARACALDO, J.S.C. \& GONZALES, J.M.M. \& GARCIA-LOMAS, J.M.S. La Biopsia en Estomatologia. Rev. Actual Estomat. Espanhola, Madri, n: 324, p. 49-62, maio, 1987.

6. HALL, H.D. Princípios de Ciruraia. In: KRUGER, G.O. Cirurgia Bucal Maxilo Facial, 5 ed., Rio de Janeiro, Guanabara Koogan, 1984, 546 p., Cap. 1, p. 1-6.

7. KESZLER, Alícia. Biópsias: Normas Practicas para su correcta obtención. RADA, Buenos Aires, v. 76, n: 111 , p. 100, junho, 1988.

8. LORANDI, César S. Biópsia das Lesőes da Região Buco-Maxilo-Facial. In: EBLING, Hardy. Cistos e tumores odontogennicos, Porto Alegre, UFRGS, McGrawhill, 1977, 183 p.,
Cap. 2, p. 28-36.

9. MILLER, Artur S. \& FANTASIA, J.E. Survey of tissue - Diagnostic Services in United States Dental Schools - 1985, Oral Surg. Oral Med. Oral Pathol., n. 2, p. 225-227, fevereiro, 1988.

10. SCHELKUN, P. M. \& GRUNDY, W.G. Fine needle aspiration biopsy of head and neck lessions, J. Oral Maxillofac, Surg., n: 49, p. 262-267, março, 1991.

11. SHAFER, W. \& HINE, M. \& LEVY, B. Tratado de Patologia Bucal, 3 ed., Rio de Janeiro, Interamericana, 1979, 837 p., Seção III Agressão e Reparo, Cap. 11, Cicatrização das Feridas Bucais, p. 549-568. 